\title{
Un periódico neoyorquino como vehículo ideológico de promoción del español. El caso de La Prensa (1917-1928) ${ }^{1}$
}

\author{
Rosa Sánchez* \\ Swiss National Science Foundation
}

\begin{abstract}
Resumen
En el presente artículo se da a conocer material publicado en el periódico neoyorquino La Prensa para promocionar el español y su enseñanza entre los años 1917 a 1928. Se trata de un corpus bastante heterogéneo constituido por material publicitario, material didáctico (cursos de lengua y rúbricas que proporcionaban textos sobre y para las aulas) y concursos, que tiene en común la promoción del español y su enseñanza como estrategia comercial para la ampliación de los lectores durante un periodo en el que en EE.UU. se vive lo que se ha denominado un Spanish craze o hispanomanía. Se presentan los factores históricos, geopolíticos e ideológicos que llevaron a que el español se convirtiera en la primera segunda lengua enseñada en el
\end{abstract}

1 Este artículo ha sido elaborado durante una estancia de investigación afiliada al programa doctoral Hispanic and Luso-Brazilian Literatures and Languages del Graduate Center de la City University of New York en el marco del proyecto Constructing Communicative Spaces. Self-representation and Linguistic Diversity in New York's Spanish-language Press during the First Half of the 20th Century (Advanced Postdoc.Mobility-Project: P3001P1_151221) financiado por el Fondo Nacional Suizo para la Promoción de la Investigación (SNF; http:// www.snf.ch/).

* Para correspondencia, dirigirse a: Rosa Sánchez (rosa.sanchez@unibas.ch),The City University of New York, The Graduate Center, Ph.D. Program in Hispanic and Luso-Brazilian Literatures and Languages, 365 Fifth Avenue, New York, NY 10016, USA. 
sistema escolar estadounidense, para luego ilustrar las estrategias mediante las cuales el periódico se hizo eco en sus contenidos de las ideologías divulgadas por las instituciones culturales más importantes de la época (Hispanic Society, American Association of Teachers of Spanish, Instituto de las Españas de la Columbia University) y con las cuales llegó a colaborar en determinados formatos.

Palabras clave: ideologías lingüísticas, prensa hispana, enseñanza del español, La Prensa, Nueva York, José Camprubí.

A New York Newspaper as Ideological Vehicle for the Promotion of Spanish. The Case of La Prensa (1917-1928)

\begin{abstract}
The current article presents and analyzes material promoting Spanish and its teaching published between 1917 and 1928 in La Prensa,one of New York's leading Spanish-language newspapers. The corpus consists of a series of heterogeneous texts such as advertisements, didactic material and competitions, having in common the promotion of Spanish and its teaching as a commercial strategy in order to expand its readership during a time when the US was experiencing a Spanish craze. Furthermore, historical, geopolitical and ideological factors are presented that led Spanish to be the first foreign language taught in the American school system. The article also shows how the newspaper reflected and adapted itself to the ideologies displayed by the main cultural institutions it collaborated with, such as the Hispanic Society, the American Association of Teachers of Spanish, and the Instituto de las Españas at Columbia University.
\end{abstract}

Keywords: language ideologies, Hispanic press, Spanish as a foreign language, La Prensa, New York, José Camprubí.

Recibido: 13/09/2016 Aceptado: 30/06/2017

Durante el mes de febrero de 1917, el periódico La Prensa se promocionaba en la cabecera con el siguiente lema: "The best medium to practice Spanish". A primera vista esto puede sorprender o parecer contradictorio, pues tratándose de un periódico que ha sido definido como de y para inmigrantes (Kanellos 2000: 32 y ss.) lo esperable sería que promocionase el aprendizaje del inglés como soporte para la integración de los inmigrantes en la sociedad de acogida; cosa que también hizo, pero en menor medida. 
Tras presentar brevemente el periódico y su director, veremos a continuación los motivos históricos y socioculturales que hicieron que este rotativo, uno de los más importantes (sino el más importante, al menos durante este periodo) dentro de la panorámica periodística hispanófona neoyorquina, pusiera un gran énfasis en la promoción de la enseñanza de la lengua española, sobre todo entre 1917 y 1928. Después de esto presentaremos un breve marco teórico en el que relacionaremos los dos ámbitos aquí tratados -el periodístico y el didáctico- con una serie de herramientas teóricas que nos serán útiles para el análisis del material recolectado. En la última parte describiremos y analizaremos estas, que identificamos como estrategias comerciales, puestas en marcha por el rotativo.

\section{LA PRENSA Y JOSÉ CAMPRUBÍ}

El periódico La Prensa ${ }^{2}$ fue fundado el 12 de octubre 1913 por el español Rafael Viera y Ayala y su propósito inicial fue "contrarrestar «las malas doctrinas publicadas por varios periódicos anarquistas que se publica[ba]n en español en la ciudad de Nueva York»" ${ }^{3}$. Poco se sabe de esta primera etapa fundacional, ya que no se conservan, que sepamos, números de ella (cfr. de Juan Bolufer 2009: 534 y ss.). Tras una serie de cambios internos y de propietarios, será durante el año 1917, con la llegada de José Camprubí (1879-1942) ${ }^{4}$, un ingeniero español-puertorriqueño ${ }^{5}$, que este órgano, aún modesto y de difusión semanal, se convertirá finalmente en diario, el 04 de junio 1918. Es aún incierto cuándo Camprubí realizó exactamente la compra del periódico, tuvo que ser entre los años 1917-1919 (de Juan

2 Para más información véase también la cronología que El Diario / La Prensa elaboró para su centenario en 2013: <http://centenario.eldiariony.com/cronologia/)>.

3 En $<$ http://centenario.eldiariony.com/cronologia/) $>$. Según la información que se encuentra en esta misma página web, Viera era canario y llegó a Nueva York en 1910 pasando por La Habana, donde ya había fundado un periódico. En 1920 dirigió además otro semanario neoyorquino, La Gaceta, también por poco tiempo.

4 Para más información acerca de la vida de José Aymar Camprubí véanse de Juan Bolufer (2009), Cortés Ibáñez (2013) y Fernández y Cagiao (2016).

5 Recordemos que la isla de Puerto Rico había sido cedida por parte de España a Estados Unidos en 1898 a raíz de la pérdida de la Guerra hispano-estadounidense, según lo acordado en el Tratado de París. 
Bolufer 2009: 537; Cortés Ibáñez 2013: 5) ${ }^{6}$. El caso es que no será hasta 1921 que abandonará sus otras ocupaciones laborales para dedicarse por completo a la dirección del diario. Durante este periodo, la empresa "La Prensa Printing Co." (fundada en enero de 1919) se hará con una imprenta propia y tanto el servicio cablegráfico, como la plantilla laboral y las instalaciones técnicas serán ampliados, fruto de todo lo cual se aumentarán las tiradas de 5000 ejemplares en 1918 a 13000 en 1921 (de Juan Bolufer 2009: 537, según indicaciones del propio periódico). A lo largo del año 1920 se empieza a publicar en el directorio una lista de países para los cuales el rotativo ofrece suscripción, la lista se va ampliando hasta llegar en 1928 a los siguientes países: "Estados Unidos y posesiones, Argentina, Bolivia, Brasil, Canadá, Chile, Colombia, Costa Rica, Cuba, Ecuador, El Salvador, España, Guatemala, Honduras, Méjico, Nicaragua, Panamá, Paraguay, Perú, Santo Domingo y Uruguay" (p. ej. 18.12.1928, 4a). Con la debida cautela ante los datos proporcionados por el periódico, esto nos puede dar una idea, ya no tanto del ámbito de difusión que pudo tener efectivamente, sino más bien del ámbito de difusión aspirado o deseado por parte del rotativo.

Camprubí, que había sido director de la Unión Benéfica Española (UBE) ${ }^{7}$ desde 1914, usó el rotativo desde 1917, “como plataforma de información de los derechos de los hispanos en los Estados Unidos" (de Juan Bolufer 2009: 537). La compra y las funciones informativas comunitarias del periódico se hicieron aún más urgentes cuando, desde la entrada de EE.UU. en la Primera Guerra Mundial, muchos barones hispanos fueron acusados de desertores y la oficina de abogados defensores establecida por la UBE no daba abasto con la atención. Según el propio Camprubí:

tanta gente fué la que vino, que se hizo imposible atenderla, y había que darle un número de orden y decirles que se les llamaría. Para esto era necesario un periódico y compré LA PRENSA, y en los números de aquella época pueden verse los anuncios llamando a los reclutas (“Autobiografía del Director de «La Prensa»", 06.06.1938, 10e) ${ }^{8}$.

\footnotetext{
6 Según Fernández y Cagiao (2016) la compra se efectuó ya en 1917.

7 Fundada en 1914, la "Unión Benéfica Española. Sociedad de Beneficencia, Protección, Instrucción y Recreo. Única Reconocida y Subvencionada por el Gobierno de España" fue durante mucho tiempo la asociación más importante para la ayuda e integración de inmigrantes españoles e hispanoamericanos en NYC (cfr. Cortés Ibáñez 2013).

8 Esta autobiografía se publicó a raíz del 25 aniversario de La Prensa, se volvería a reeditar a raíz de la defunción de Camprubí en la edición del 13.03.1942, 1d-f.

Manejamos ejemplares de la New York Public Library y del archivo del Center for Puerto Rican Studies de la City University of New York. En las referencias del periódico indicamos
} 
Este destacado miembro de la colonia hispano-neoyorquina fue asimismo miembro de las sociedades más importantes de la ciudad tales como la Hispanic Society ${ }^{9}$, el Instituto de las Españas de la Columbia University, la Pan American Society o la Spanish Chamber of Commerce y la Pan American Business Association (de Juan Bolufer 2009: 538). Como ingeniero, empresario y periodista fueron múltiples las esferas en las que se movió: la intelectual, la social-cultural, la comercial; "era liberal y demócrata por convicción y republicano aún desde los tiempos de la monarquía" (13.03.1942, 1c), de ideología moderada y ecléctica (Fernández y Cagiao 2016), siempre a caballo entre el proyecto hispanista y el panamericanista (cfr. cap. 2.). Estuvo casado con Agnes Ethel Leaycraft, prima de tercer grado de Theodore Roosevelt y fue hermano de la escritora Zenobia Camprubí, esposa de Juan Ramón Jiménez.

Todo estos aspectos biográficos se reflejarán por supuesto también en los contenidos del periódico. El programa de La Prensa fue desde un comienzo, por una parte, el "de servir a la colonia española e ibero americana en Estados Unidos" (18.11.1922, 1d), informando y ofreciendo servicios para unificar esta comunidad por esos entonces ya bastante heterogénea ${ }^{10}$. Por otra parte, el periódico también se vio como embajador del mundo hispano, queriendo "servir a todos los norteamericanos que tienen interés en nuestro arte, cultura, comercio y civilización en general" (18.11.1922, 1d); en un ejercicio constante de tender puentes entre ambas sociedades: la de origen y la de acogida y las comunidades resultantes del movimiento migratorio. Como declaraba el mismo rotativo: "Este diario es Ibero-Americano y especializado en España, Portugal, las 19 Repúblicas Iberoamericanas, Puerto Rico, Filipinas, Los Estados Unidos y Canadá" (06.06.1938, 11a).

El 12 de marzo de 1942 fallece Camprubí; años después, en 1960, sus hijas venderán el diario al empresario Fortune Pope, cuya familia

fecha de publicación, página y columna. En las citas reproducimos la (orto)grafía tal cual, corrigiendo simplemente las erratas tipográficas más evidentes. Las cursivas son del periódico, de ser nuestras lo indicamos en nota a pie de página.

9 De esta fue, de hecho, miembro correspondiente desde diciembre de 1919 y miembro de derecho desde noviembre de 1939, hasta finalmente "ser elegido miembro de honor unos días antes de morir, el 7 de marzo de 1942", lo cual le concedió el "privilegio de estampar su firma en una de las columnas del museo" (de Juan Bolufer 2009: 540).

10 Para más información acerca de la composición demográfica de la comunidad hispanoneoyorquina de la época, véase Haslip-Viera (1996: 8). Durante los años 1920 los grupos más representados eran oriundos de España, Cuba y Puerto Rico, en este orden, orden que se invertirá a lo largo de las décadas siguientes, cuando la población boricua se irá perfilando como la más numerosa, debido a los sucesos geopolíticos en la Isla. 
era propietaria desde 1928 del también diario neoyorquino Il Progresso Italiano-Americano $(29.03 .1960,2 \mathrm{c})$. Con todo, la era Camprubí, que es la que aquí trataremos, se puede considerar como una etapa muy fructífera para el rotativo al expandir y profesionalizar sus servicios a pesar de las carencias económicas por las que también tuvo que pasar (cfr. cap. 4.1.). Se puede decir que el diario fue una publicación general de tipo informativo, de ideología moderada y ecléctica (Fernández y Cagiao 2016), al igual que su propietario, tratando de alcanzar un máximo de lectores (de un nivel más bien culto) dentro de la colonia hispano-neoyorquina y fuera de esta, tal como demuestra también el material que analizaremos a continuación.

En 1963, La Prensa se fusionará con El Diario de Nueva York, diario que se había fundado en 1948 y que en pocos meses se había afianzado en el mercado periodístico neoyorquino. El propietario por esos entonces era el magnate O. Roy Chalk, que había adquirido a su vez El Diario de Nueva York en 1961 a su fundador, el dominicano Porfirio Díaz y La Prensa en 1962. El resultado de la fusión, El Diario / La Prensa (recientemente ya solo El Diario), sigue existiendo aún hoy en día, pertenece a la multinacional ImpreMedia desde 2004 a la cual también pertenecen periódicos tales como La Opinión (Los Ángeles), La Raza (Chicago) o La Prensa (Florida), entre otros $^{11}$.

\section{CONTEXTO HISTÓRICO-IDEOLÓGICO}

Serán una serie de factores de índole histórica, geopolítica, socioeconómica y cultural (cfr. tb. Fitz-Gerald 1917: 11; de Onís 1920: 275 y s.) los que hagan que durante las primeras décadas del siglo xx se viva en EE.UU. lo que Kagan ha denominado un Spanish craze o hispanomanía:

The term refers to a particular era in US history when seemingly everything Spanish -art, music, language, literature, architecture, and more- was in vogue. This particular "craze" began in the 1890s, and lasted, with few interruptions until the early 1930s, when it was brought to an abrupt end by a combination of factors associated with the Great Depression, the victory of General Francisco Franco and his Falange

11 Cfr. <http://www.impremedia.com/\#intro> y Yúdice (2009: 56 y s.). 
Party in Spain's bloody civil war (1936-1939), and changing tastes and fashions in the United States (2010: 38).

Este será en realidad un segundo boom de hispanofilia; el primero había tenido lugar ya durante el siglo XIX y había sido fomentado por una serie de filólogos estadounidenses, estudiosos de lenguas modernas, entre ellas el español, tales como Washington Irving, Henry Wadsworth Longfellow, William H. Prescott o George Ticknor entre otros (Wilkins 1922: 133; RuizManjón 2012: 399; cfr. Jaksic 2012).

Dos guerras desempeñarán un papel fundamental en este segundo auge. Por una parte será, paradójicamente, de gran importancia la derrota de España en la Guerra hispano-estadounidense y la pérdida de sus últimas colonias para la revaloración de todo lo español en EE.UU:

Spain's defeat in the Spanish-American war eliminated the idea that Spain might somehow be a threat to hemispheric security, and it was arguably the removal of this "threat factor" that helped clear the way for a new and intensified Spanish craze in the US. [...]But it is almost as if once Spain had been definitively expelled -as a political player- from the hemisphere, and once the US had begun to imagine itself as the seat of a new kind of benign and enlightened empire, certain Spanish cultural forms -which before may have seemed backward or decadent- could now be safely reinscribed or re-appropriated as exotic or picturesque or even stately (Fernández 2010: 57).

Por otra parte, desempeñará un papel fundamental la entrada de EE.UU. en la Primera Guerra Mundial en 1917 en el "intensified interest in the spiritual and political ideals of the twenty other sovereign states in the western hemisphere, in eighteen of which Spanish is the official language" (Fitz-Gerald 1917: 11). Este interés por los países americanos hispanófonos no fue aleatorio; la gran guerra había dificultado el comercio con Europa lo cual llevó a que EE.UU. tuviera que centrar sus intereses comerciales, ahora más que nunca, en el hemisferio sur, ruta que había sido facilitada gracias a la apertura del Canal de Panamá en 1914.

Se puede vincular cada una de las guerras, de alguna manera, a uno de los movimientos ideológicos que surgen durante el siglo XIX en el mundo hispano. Si bien el movimiento del hispanismo (también llamado hispanoamericanismo $)^{12}$ surge ya durante el segundo tercio del siglo XIX,

12 Según Sepúlveda Muñoz, se trata de una idea transnacional y de un movimiento que a su vez se puede subdividir en tres corrientes: "la pan-hispanista, la progresista y la propiamente 
las consecuencias de la derrota de la Guerra hispano-estadounidense y la consecutiva pérdida de los últimos territorios de ultramar españoles, sentarán las bases para su posterior desarrollo (Sepúlveda Muñoz 1994: 50 y ss.). El hispanismo postulaba la pertenencia de españoles e hispanoamericanos a una misma raza, una raza formada por una cultura, una historia, tradiciones y una lengua compartidas, más que por sangre o factores étnicos (cfr. Pike 1971; Sepúlveda Muñoz 1994). Este movimiento ha sido interpretado como una reacción al imperialismo cultural, económico y político de EE.UU. (Fernández 2002: 133; Sepúlveda Muñoz 1994: 275 yss.). Sorprendentemente, es en este país donde tuvo uno de los mayores impactos y una interpretación muy propia, debido, por una parte, precisamente a la pérdida de la amenaza por parte de España y, por otra, a la articulación ideológica con el movimiento panamericanista.

Este último surge a raíz de las guerras de independencia de los países hispanoamericanos y adquiere un carácter más o menos oficial en los EE.UU. a través de la Doctrina Monroe. El bloqueo comercial hacia Europa causado por la Primera Guerra Mundial fomentará aún más las relaciones verticales con las jóvenes naciones hispanoamericanas, reforzando el carácter económico que había adquirido el interés por el español en el marco del panamericanismo estadounidense.

Pero, según los intelectuales hispanófilos e hispanistas de la época, fueron precisamente el aliciente práctico-comercial del panamericanismo en Latinoamérica ${ }^{13}$, junto con la imagen de una España sujeta a retraso y decadencia vinculada a la leyenda negra, los principales factores que hicieran que el español careciera inicialmente de estimación, al menos durante las dos primeras décadas. Por lo cual hubo que lanzar toda una campaña para dotar a esta lengua de prestigio, como se había hecho previamente con otras lenguas como, por ejemplo, el alemán. En estos términos lo planteaba uno de los miembros de la American Association of Teachers of Spanish (AATS) ${ }^{14}$, Jacob Warshaw, en Hispania, la revista órgano de esta asociación:

americana" (1994: 30). El episodio estadounidense parece inscribirse más bien en la corriente progresista (cfr. Sepúlveda Muñoz 1994: 118 y ss.). Para las diferentes denominaciones de este movimiento véase Sepúlveda Muñoz (1994: 25-30).

13 Lo cual no quita que también determinadas vertientes del hispanismo tuvieran un marcado interés en las relaciones comerciales con Latinoamérica (cfr. Sepúlveda Muñoz 1994: 37 y ss.).

14 Agradecemos a Inés Vañó García, que en la actualidad está realizando una tesis sobre la AATS, las informaciones que nos ha proporcionado acerca de esta asociación. Warshaw ocupó diferentes cargos importantes dentro de la AATS e Hispania. 
The extraordinary vogue of German was largely the result of efficient advertising for prestige. The popularity of French, too, has been due to prestige; but it has needed very little active propaganda in our days. French prestige is traditional, and, in general, a spontaneous and unconscious product. German prestige was made. Spanish prestige must be made (1919: 227).

Y por supuesto, la prensa será uno de los vehículos más importantes para la promoción y difusión de esta campaña, como lo declaraba también Warshaw:

Every Spanish newspaper and periodical in the United States should educate us in this respect. It is only by some such means that we shall be able to rehabilitate Spain and Spanish in the eyes of the world and acquire a portion of that "prestige" which is the dominant educational measurement (1919: 235).

El origen de dicho prestigio procederá del hispanismo y será precisamente la "madre patria", España:

No sólo por razones de comercio, sino, ante todo, porque de esta manera podemos entendernos fraternalmente con las naciones que con nosotros ocupan el nuevo hemisferio. Sirve el idioma español para promover la paz y tranquilidad interamericana y para corregir los mutuos conceptos falsos que tienden a separar los pueblos de habla española e inglesa.

El interés por la América española se encauza siempre a través de España, pues mientras más estudiamos vuestra literatura y vuestra civilización y las de Hispano-América, vemos que éstas no son más que el trasunto de las de España. Por tanto, sabemos que el mejor modo de conocer lo hispanoamericano es a través de lo español (Wilkins 1922: 155) ${ }^{15}$.

Esto será lo que James Fernández ha denominado la "Ley de Longfellow", que predice que el interés estadounidense por España siempre ha estado mediado por su interés en Hispanoamérica (2002: 135) en la siguiente distribución: "interest in Latin America was coded as being primilarily-or exclusively-driven by economics, whereas interest in Spain was marked as being driven purely by culture" (2002: 133).

Las siguientes instituciones desempeñaron un papel fundamental en dicha campaña de prestigiamiento: la Hispanic Society of America (1904;

15 Se trata de un extracto de una conferencia que Wilkins, cofundador de la AATS (cfr. infra) dio el 08.12.1921 en el Ateneo de Madrid, de ahí que hallemos marcas de interpelación. 
fundada por Archer M. Huntington $)^{16}$, la American Association of Teachers of Spanish (a partir de 1944 se le añade "and Portuguese", 1917; fundada por Aurelio M. Espinosa y Lawrence A. Wilkins; cfr. Leavitt 1967) y el Instituto de las Españas (que posteriormente pasará a llamarse Instituto Hispánico) de la Columbia University (1920; dirigido por Federico de Onís; cfr. de Onís 1955: 8 y s., 1968: 732 y ss.); que surgen en Nueva York a comienzos del siglo del siglo xx como reflejo y reacción a este boom de hispanofilia y a la creciente demanda de aprendizaje de esta lengua (cfr. infra). Estas eminentes instituciones neoyorquinas estuvieron en estrecho contacto con las instituciones más importantes españolas creadas por las reformas que había llevado a cabo la Junta para Ampliación de Estudios e Investigaciones Científicas (JAE, 1907), a saber, sobre todo el Centro de Estudios Históricos (CEH, 1910), cuyo director era por esos entonces el ilustre filólogo, miembro y en diferentes ocasiones director de la Real Academia de la Lengua Española, Ramón Menéndez Pidal:

Con la nueva institución, heredera de los principios de la Institución Libre de Enseñanza, se pretendía terminar con el aislamiento español y enlazar con la ciencia y la cultura europeas, además de preparar al personal encargado de llevar a cabo las reformas necesarias en las esferas de la ciencia, la cultura y la educación. De este modo, el esfuerzo por reformar, por regenerar el país, pasaba a ser una empresa nacional, independiente de los vaivenes políticos, en la que se implicaba a intelectuales de diferente ideología.

Para llevar a cabo estos objetivos la JAE puso en marcha una activa política de pensiones, esenciales para el desarrollo cultural y científico de España, de la que se beneficiaron numerosos estudiantes, profesores e investigadores, que fueron becados para trabajar en el interior, en Europa y en América (en: < http://www.jae2010.csic.es/historia.php>).

Esta voluntad de ruptura con el aislamiento y regeneración de las ciencias y educación se plasmó de diferentes maneras en el caso del hispanismo estadounidense. Por una parte, mediante el estrecho intercambio, p. ej., en cursos de verano en Madrid, de profesores de español de todos los niveles del sistema escolar estadounidense (Fitz-Gerald 1917). Por otra parte, los catedráticos de Filología Hispánica en EE.UU. eran por esos entonces casi todos enviados por este órgano (cfr. Wilkins 1922: 101).

16 Cfr. $<$ http://www.hispanicsociety.org/hispanic/history.htm>. 
Así nos relata el que fue durante años director de la Enseñanza de Lenguas Modernas en las Escuelas Superiores de la ciudad de Nueva York y cofundador de la AATS, Lawrence A. Wilkins (cfr. tb. de Onís 1968: 722724) los cambios que se produjeron en el ámbito de la enseñanza de lenguas:

Mientras tanto, había explotado la gran guerra, y en nuestro pequeño mundo lingüístico-pedagógico ocurrió, como en otros muchos mundos del planeta, un trastorno completo. Desde 1914 hasta 1918 se manifestó un verdadero cataclismo en nuestra enseñanza de lenguas, que dejó por resultados los siguientes: $1 .^{\circ}$ decadencia del alemán, que había ocupado el primer lugar en el programa de casi todas las instituciones docentes del país, decadencia tan marcada que poco faltó para que desapareciese por completo la enseñanza de este idioma; $2{ }^{\circ}$ ascensión del francés al puesto de lengua predilecta en la mayor parte de las Universidades y escuelas secundarias; $3 .^{\circ}$ aumento casi increíble de la adhesión al castellano, llegando esta lengua a ocupar el primer puesto en muchas partes y en otras corría parejas con el francés y en todas partes excedía al alemán en el número de los que estudiaban. En mi opinión, no depende la boga del español en los Estados Unidos de la popularidad ni del decaimiento de ningún otro idioma. Se ha logrado un lugar tan importante que no hay nada que pueda destituirlo en la presente generación (1922: 29 y s.).

Este auge del español se traducía en materia de números de la siguiente manera, por ejemplo, en el nivel de las "high schools de la ciudad de Nueva York" (Wilkins 1922: 49):

\begin{tabular}{|c|c|c|c|c|c|}
\cline { 2 - 6 } \multicolumn{1}{c|}{} & Francés & Alemán & Italiano & Latín & Español \\
\hline 1917 & 14.000 & 23.000 & 103 & 17.000 & 13.900 \\
\hline 1918 & 17.000 & 13.000 & 56 & 16.000 & 21.000 \\
\hline 1919 & 20.000 & 3.000 & 66 & 15.000 & 25.000 \\
\hline 1920 & 20.000 & 500 & 125 & 14.000 & 28.000 \\
\hline 1921 & 22.000 & 800 & 213 & 13.000 & 31.000 \\
\hline
\end{tabular}

Es perceptible a partir de las cifras un claro descenso de inscripciones para el alemán, así como un ascenso para las lenguas románicas, sobre todo para el español.

En el nivel universitario podemos mencionar las cifras de matrículas en español de la Columbia University que nos proporciona Federico de Onís (adaptado de 1968: 729): 


\begin{tabular}{|c|c|c|c|c|c|}
\hline $1903-1904$ & $1911-1912$ & $1914-1915$ & $1915-1916$ & $1916-1917$ & $1920-1921$ \\
\hline 50 & 248 & 596 & 763 & $\begin{array}{c}1626 \\
(72 \\
\text { graduados, } \\
1512 \text { no } \\
\text { graduados) }\end{array}$ & $\begin{array}{c}2.923 \\
\text { (no } \\
\text { graduados) }\end{array}$ \\
\hline
\end{tabular}

En lo que sigue veremos cómo nuestro rotativo se hizo eco de todo lo hasta aquí expuesto: las ideologías recurrentes, la campaña de prestigio, el aumento del profesorado y alumnado de español, etc.

\section{MARCO TEÓRICO}

Los dos ámbitos que abordaremos a continuación, el periodístico y el de la enseñanza de lenguas extranjeras (ELE), comparten diferentes características y funciones en la sociedad y con respecto a la lengua y sus implicaciones económicas y políticas ${ }^{17}$. Se trata en ambos casos de esferas que promueven discursos y prácticas que tienen que ver con la estandarización de formas y normas lingüísticas, también desempeñan un papel fundamental en la producción y reproducción de ideologías lingüísticas y, por último, aportan de manera sustancial al proceso de mercantilización de las lenguas.

Si los discursos mediáticos representan ya de por sí espacios discursivos o actividades en las que determinados agentes sociales deciden sobre la legitimidad de la(s) lengua(s) y de los hablantes (cfr. tb. Cameron 1995: 11):

We can think of the media as one of these [discursive spaces], and ask questions about the kind of discursive space it is, who controls it, what kinds of interest they may have in defining linguistic competence the way they do, and what consequences this may have for ranges of speakers who control diverse arrays of linguistic resources (Heller 2010a: 278),

17 Por todos estos motivos, el material recolectado se presta perfectamente para un análisis desde la perspectiva de la glotopolítica, que es una rama de la sociolingüística que se dedica a estudiar las articulaciones entre la lengua y las dimensiones políticas que ésta suele implicar (cfr. p. ej. del Valle 2007; Arnoux 2008; Arnoux y del Valle 2010; del Valle 2013 y 2014b). 
lo mismo es válido para el ámbito de la enseñanza de lenguas en el que operan, como afirma Pennycook (1989), diferentes relaciones de poder en un complejo nexo de relaciones de factores sociales, culturales, económicos y políticos. También aquí se legitiman determinadas variedades o lenguas con respecto a otras en un mercado lingüístico (Bourdieu 1977, 1992) debido al valor simbólico que determinados regímenes lingüísticos (Kroskrity 2000) le adjudican.

Ambos ámbitos funcionan como importantes agentes o instituciones que contribuyen a la organización lingüística de la esfera pública y de los grupos sociales que la constituyen (cfr. Habermas 1974; Paffey 2012: 44; LippiGreen 1997: 55), por lo tanto, participan en los procesos de planificación, regulación y estandarización de una lengua (Joseph 1987: 14; Paffey 2012: 48). Primero la enseñanza (Bourdieu 1977), luego los medios, desempeñan un importante papel en la normalización de este estándar. De esta forma contribuyen a la construcción y reglamentación del ciudadano y de la naciónEstado en la que éste se inserta (cfr. tb. Paffey 2012: 40):

The media has played a key role in this joint process of constructing nation, State, Empire, citizen and subject, and in producing the legitimating ideologies of the social order. We can understand 'language ideologies and media discourse' in precisely these terms, namely as a field in which the media serves as one institution for the construction of citizens, one dimension of which is their linguistic practice (Heller 2010a: 278).

Son por ende asimismo importantes espacios discursivos en la producción y reproducción de ideologías lingüísticas (Paffey 2012: 74) mediante prácticas lingüísticas, pero también a través de discursos metalingüísticos. Entendemos por ideologías lingüísticas

sistemas de ideas que articulan nociones del lenguaje, las lenguas, el habla y/o la comunicación con formaciones culturales, políticas y/o sociales específicas. Aunque pertenecen al ámbito de las ideas y se pueden concebir como marcos cognitivos que ligan coherentemente el lenguaje con un orden extralingüístico, naturalizándolo y normalizándolo (van Dijk 1995), también hay que señalar que se producen y reproducen en el ámbito material de las prácticas lingüísticas y metalingüísticas, [...] (del Valle 2007: 19 y s.).

La naturalización de ideologías se consigue muy a menudo precisamente mediante la reproducción y repetición de éstas en los medios y en la enseñanza, entre otros (cfr. Paffey 2012: 34 y s.; del Valle y MeirinhoGuede 2016: 622). Otra herramienta importante para nuestro análisis será 
el concepto de ideologema que puede ser considerado como herramienta básica o materialización discursiva de las ideologías lingüísticas. Se trata más concretamente de

lugares comunes, postulados o máximas que, pudiendo realizarse o no en superficie, funcionan como presupuestos del discurso. Se pueden identificar los ideologemas dominantes en una época, en un campo discursivo o en una institución ${ }^{18}$ (Arnoux y del Valle 2010: 12).

La suma de ideologemas conforma el sistema lingüístico-ideológico de una determinada comunidad de habla (del Valle y Meirinho-Guede 2016).

Otra cosa que tienen en común la prensa y la enseñanza de segundas lenguas es que ambas actividades probablemente siempre han participado y participan cada vez más en la actividad de mercantilización (commodification) de la lengua como producto con valor económico (Bourdieu 1977). Según Heller (2010b: 105), con la nueva economía globalizada la emergencia del trabajo lingüístico (language work) y del trabajador lingüístico (language worker) se han convertido en factores centrales dentro de la sociedad. En lo que sigue veremos, no obstante, cómo estas tendencias se fueron fraguando ya durante la época preglobalizada.

\section{MATERIAL Y ASPECTOS METODOLÓGICOS}

A continuación presentaremos y analizaremos parte del material publicado en el periódico La Prensa mediante el cual se promocionó activamente durante dicho periodo el español y el aprendizaje de esta lengua, inscribiéndose así en lo que se ha pasado a denominar a posteriori Spanish craze. Se trata de un corpus de tipos y géneros textuales bastante heterogéneos, que podríamos clasificar bajo las siguientes rúbricas: material publicitario, material didáctico y concursos. Seguimos con ello el modelo de Grosse y Seibold (1994) (cfr. tb. Grosse 2001) que abarca en su tipología de géneros periodísticos también los no propiamente periodísticos (strictu sensu) por formar parte integrante de la macroestructura periodística. En los tres casos se trata de estrategias

\footnotetext{
18 Son por ejemplo ideologemas ambos postulados recurrentes durante las primeras décadas del siglo xx acerca del valor práctico/económico y el valor cultural/prestigioso del español y que conjuntamente configuraron esta articulación/triangulación entre panamericanismo e hispanismo tan propia de los ámbitos intelectuales estadounidenses.
} 
comerciales que pueden ser fuente de ingresos directos y/o mediante las cuales se trata de atraer o involucrar de manera más activa a los lectores. En el caso del material didáctico, que a su vez se subdivide en cursos de lengua y en la rúbrica "El Eco de las Aulas" se podría decir que los primeros van a caballo entre los servicios/consejos y la publicidad, mientras que el segundo constituye (al menos en su época inicial) un cajón de sastre que contiene de todo un poco (información, consejos, ficción, divertimiento y publicidad).

Disponemos de números de los años 1917 a 1963, cuando el periódico se fusiona con El Diario de Nueva York. Lamentablemente no se conservan, que sepamos, los números de los primeros 4 años de andanza de La Prensa, que empezó a publicarse, como ya hemos dicho, el 12 de octubre de 1913. Los primeros números disponibles en la New York Public Library datan de enero de 1917. Para el presente artículo nos hemos limitado al periodo que comprende los años 1917 a 1928 (año en el que se cesa de publicar "El Eco de las Aulas"), que es el periodo en el que el periódico parece adherirse de manera más manifiesta al boom hispanófilo.

\subsection{Material PUBLICITARIO}

No ahondaremos demasiado en este apartado. Baste con decir que en $L a$ Prensa se publicitaron, como era y sigue siendo usual en este tipo de prensa, que se ha denominado de y para inmigrantes (Kanellos 2000: 32), material y servicios para la integración del inmigrante, tales como intérpretes, servicios de corrección y redacción de textos, maestros y cursos de lengua o la venta de libros destinados a la enseñanza tanto del español como del inglés (e incluso de otras lenguas), tanto en la rúbrica de clasificados como distribuidos por las páginas del resto del periódico. Sabido es de sobra que ésta era y sigue siendo una importante fuente de ingreso, junto a los trabajos de imprenta (cfr. p.ej. 13.10.1917, 5d-e) para las empresas periodísticas, que aporta más ingresos que la venta de los periódicos mismos (Grosse 2001: 39) y tratándose, al menos durante esta época y en este contexto específico, de empresas pequeñas, que casi siempre tenían que luchar por su subsistencia. Este fue también el caso particular de La Prensa que "siempre dio problemas económicos a Camprubí" (Cortés Ibáñez 2013: 5), el cual tuvo que invertir más de una vez capital propio para mantener el periódico a flote. El propio Camprubí afirmaba en un artículo autobiográfico a raíz del vigésimoquinto aniversario del periódico: "Nunca hemos tenido subvención de ningún Gobierno. Vendemos anuncios y periódicos y NADA MÁS" (06.06.1938, 11a) (cfr. tb. p.ej. 29.05.1920, 1d-e "HOY EL ANUNCIO ES EL MEDIO 
MAS IMPORTANTE" o 18.06.1920, 1d-e "EL CENTRO DEL MERCADO HISPANICO" publicidad para anunciar en las columnas clasificadas).

No nos extraña, pues, que el periódico recurriera además a estrategias publicitarias tales como la de promocionarse en la cabecera como "The best medium to practice Spanish" durante el mes de febrero de 1917. Asimismo encontramos durante el año 1918 publicidades para el periódico mismo en las que se puede leer "Read and practice Spanish, the language of the future" (p. ej., el 02.12.1918, 6f-g). Ya nada más por el mero hecho de estar redactada en inglés, este tipo de llamada estaba claramente dirigida a un potencial consumidor anglófono, probablemente uno que estuviera interesado en aprender español por motivos comerciales (cfr. nota 27) u otros motivos. También puede que estos reclamos estuvieran vinculados a la práctica de emplear el periódico en las aulas de aprendizaje de lenguas, como estudiaremos en el próximo apartado.

La suscripción al periódico a veces era además premiada mediante el obsequio de un libro, como podemos observar durante el mes de enero de 1922, en colaboración con la librería Zabala y Maurin (en 135 West 49th): "Regalamos un libro de Amado Nervo, Azorín, Blasco Ibáñez o Pio Baroja, con una subscripción diaria de seis meses a LA PRENSA o Dos de los siguientes libros versiones castellanas" $(19.01 .1922,4 \mathrm{~g})$ o durante los años de 1919 y $1920^{19}$ mediante el obsequio de un diccionario por cada suscripción anual (p. ej., 18.09.1919, 4e-g).

Vemos, pues, cómo desde ya muy temprano este periódico se apropia de este tipo de estrategias publicitarias, tratando la lengua y el aprendizaje de ésta como un producto de mercancía, ya antes de que la globalización hiciera de este ámbito todo un gran mercado lucrativo (cfr. Heller 2010b).

\subsection{Material didÁctico}

El artículo de Alfred Coester, otro destacado miembro de la AATS (cfr. Devenish Walsh 1967: 824), publicado en 1918 en uno de los primeros números de Hispania, titulado "Periodicals in Spanish Available for the Classroom", da fe de que la práctica de emplear periódicos y revistas en el aula de aprendizaje de lenguas era ya usual durante esa época (cfr. tb.

19 Durante este año el periódico lamenta el retraso de la entrega de éstos debido a la "escasez del papel y la huelga de ferrocarriles" (03.05.1920, 8c-e); al parecer estas obras eran impresas en la propia imprenta. 
Oakley 1919: 296 y s.). Coester veía determinadas ventajas en usar los periódicos hispanófonos publicados en EE.UU. (vs. los publicados en países hispanófonos):

A magazine printed in the United States will probably prove most satisfactory for classroom use. Though it will not have a tone so thoroughly Spanish as those printed abroad, it will be received with greater regularity; and in case a teacher wishes to use a large number of a single issue, they can be obtained more easily and economically (1918: 26).

Quedamos ante la duda de cómo interpretar el sintagma "it will not have a tone so thoroughly Spanish as those printed abroad", si se refiere a la autenticidad o a la calidad lingüística de los periódicos neoyorquinos; sea como fuere, las ventajas de éstos eran, desde luego, la regularidad y que eran más fáciles y económicos de conseguir. La Prensa y El Heraldo son dos que recomendaba por ser de los pocos periódicos generales informativos que se publicaban por esos entonces, como diarios a pesar de ser semanarios (Coester 1918: 27).

Aparte de esta práctica general de usar el periódico precisamente como "medium to practice Spanish", La Prensa se dedicó además a publicar una serie de materiales específicos para la enseñanza del español a lo largo de las primeras décadas de su existencia, pero con especial insistencia durante el periodo de 1917 a 1928. Dentro de este material que hemos denominado didáctico hallamos a su vez dos tipos de materiales, los cursos de lengua y "El Eco de las Aulas", una rúbrica dedicada a proporcionar textos sobre y para las aulas de ELE en EE.UU. ${ }^{20}$

Ignoramos cuál pudo ser la repercusión de este tipo de material en las ventas del periódico. En el caso de los cursos de lengua suponemos que el periódico era remunerado por publicar este tipo de material, tratándose de una fuente de ingreso similar a la de la publicación de publicidades. Difícil también de evaluar la utilidad de este tipo de métodos para el aprendizaje de una lengua, teniendo además en cuenta las restricciones que ofrece el medio escrito.

20 Como ya advertía Wilkins, la "carencia de libros de texto adecuados a la nueva situación, sobre todo, en el campo del español" (1922: 30) fue uno de los problemas que se creó a raíz de este gran incremento de demanda del español. 
En todo caso, este material iba dirigido a un público más bien norteamericano-anglófono ${ }^{21}$, pues recordemos que durante este periodo el alumnado de español en EE.UU. consistía básicamente en locutores anglófonos monolingües (del Valle 2014a: 362), lo cual no quita que también el lector hispanófono pudiera aprovechar este material, como veremos a continuación, pues muy a menudo se trata de textos/listas bilingües en inglés/ español e incluso en el caso de los textos monolingües en español, el rotativo supo como promocionárselos también y además en términos patrióticos, como veremos en capítulos posteriores (cfr. cap. 4.2.2.).

\subsubsection{Los cursos de lengua ${ }^{22}$}

Uno de los primeros cursos de los que disponemos en nuestro corpus es "El Curso Galeno de Lengua Española" que se publicó entre el 20.01.1917 y el 31.03.1917, en poco más de 10 lecciones. La publicación de este material didáctico en el rotativo se concibió como acompañamiento de las clases que este profesor estaba impartiendo en Carnegie Hall ${ }^{23}$. Después de dos artículos introductorios en los que se describen y publicitan las clases (el 01. y el 07.01.1917 ${ }^{24}$, se empieza a publicar el curso en un lugar tan destacado como la segunda página, en la sección "NOTICIAS DE TODAS PARTES", ocupando las dos primeras columnas, precedido de una publicidad para las

21 Véase también el aviso en la nota 35 que es encabezado con "TO THE AMERICAN STUDENT OF SPANISH" (17.11.1917, 7a-b). Interesantemente la versión española del anuncio reza "Advertencia al Lector". Hubiera sido interesante analizar en este tipo de paratextos bilingües las diferencias entre las versiones españolas e inglesas (cfr. tb. nota 27), que demuestran que iban dirigidas a diferentes destinatarios. Lamentablemente esto excede los límites de este trabajo.

22 No hemos hallado hasta ahora en el amplio corpus de periódicos hispanófonos publicados en Nueva York del que disponemos, un fenómeno similar. Este parece ser un fenómeno específico de La Prensa, el de publicar cursos de lengua de la lengua de procedencia del público lector y no la de la sociedad de acogida, como se estilaba en la prensa de minorías de la época. Así se publicaron, por ejemplo, lecciones de yiddish e inglés durante los años 1911 y 1912 en el periódico judeoespañol La América (cfr. Scolnik 2014: 2 y s.).

23 Carnegie Hall, aparte de ser sala de conciertos y espectáculos, fue también foro público para oradores, escritores, etc. "In the days before radio and television, Carnegie Hall gave a prominent public forum to anyone with a cause" (CHNT pág. 5). Así nos podemos imaginar que también tendrían cabida cursos de lengua y otro tipo de actividades culturales/educativas en el marco de este foro.

24 Suponemos que ambos fueron escritos por la propia redacción del periódico, además en español y en inglés. Por lo tanto, podemos decir que se trata probablemente de dos casos de publicidad redaccional (Grosse y Seibold 1994: 52). Este tipo de artículos eran redactados a cambio de pago para divulgar o promocionar servicios. 
clases y seguido del siguiente texto: "In these columns will appear weekly Articles by Professor Oscar Galeno written to assist the many pupils who are taking his course of instruction at Carnegie Hall" (p. ej., 20.01.1917, 2a-b).

Deducimos, por lo tanto, que este servicio se basaba en un pacto comercial de beneficio mutuo: el profesor publicitaba sus clases en el periódico para atraer más estudiantes y el rotativo se beneficiaba a su vez de la venta de las lecciones para los estudiantes. Ignoramos quién recibiría remuneración por parte de quién o si se trataba precisamente de un acuerdo mutuo en el que nadie tenía que pagar, por salir beneficiadas, a fin de cuentas, ambas partes. Si bien en realidad es más probable que fuera la escuela de lenguas la que pagara, las dos publicidades redaccionales previas y los anuncios que acompañaban las clases apuntan más bien a ello.

Por la descripción que se nos da en el periódico, el método Galeno (registrado en 1915), de un profesor oriundo de San Francisco, consistía básicamente en repartir hojas sueltas a los alumnos con palabras e imágenes de objetos correspondientes para hacérselas repetir en voz alta, haciendo preguntas acerca de la temática ${ }^{25}$. Tuvo que tratarse de un método que combinaba el elemento gráfico con el oral mediante la repetición de vocablos, preguntas y respuestas, dictados, etc. Por la siguiente aseveración: "Viendo sus clases se cae en la cuenta de que en el aprendizaje de idiomas no es lo más importante la regla, sino el caudal lingüístico adquirido por un método objetivo tan natural como el que instintivamente sirve al niño en sus primeros balbuceos" $(06.01 .1917,2 \mathrm{a})$, pensamos que tuvo que tratarse de un método más bien inductivo, muy probablemente de tipo directo (Omaggio 1986: 57 y ss.). Por ello suponemos que las lecciones impresas en el periódico se veían como complementarias, proporcionando al estudiante pequeñas dosis de gramática (pero no solo) en un método más bien deductivo acercándose más a los métodos de gramática y traducción, el otro tipo de métodos que se estilaba durante esa época (Omaggio 1986: 54 y ss.). Así abundan pues sobre todo las frases modelo con sus respectivas traducciones ${ }^{26}$.

25 Esta técnica de visualización típica del método directo (Omaggio 1986: 57 y ss.) era también recomendaba por Wilkins: "Convienen, sobre todo en las clases de principiantes, pegar a varios objetos del aula letreros hechos por los estudiantes, en que vayan indicados en español los nombres de cosas tales como: pupitre, ventana, mesa, asiento, silla, pizarra, caja, borrador, etc." (Wilkins 1922: 88).

26 Esto los hacía útiles también para los lectores hispanófonos, los cuales, como ya mencionado, probablemente pudieran aprovechar este tipo de lecciones a la inversa para ampliar su conocimiento del inglés. 
Las algo más de 10 lecciones que publicó el por esos entonces aún semanario resultan algo heterogéneas e imaginamos que el curso disponía en realidad de más. Resulta además llamativo que la que resulta ser la última clase, la del 31.03.1917, sea desplazada a la séptima página y a las últimas columnas de ésta ${ }^{27}$. El curso pone bastante énfasis en las conjugaciones de los principales paradigmas verbales, así por ejemplo, en la primera lección se aprende a conjugar el verbo andar en las formas del presente, pretérito perfecto simple, futuro e imperativo (20.01.1917, 2a-b). También se explican los pronombres personales; de especial interés resulta la ilustración de las formas pronominales de tratamiento, pues se recurre a formas arcaizantes, como el thou inglés, para explicar el complejo sistema pronominal de formas de tratamiento del mundo hispanófono (vs. el del inglés que se reduce a you, al menos en el contemporáneo):

Tú (thou) is usted [sic] in Spanish to indicate familiarity and affection, and is used among relations, intimate friends and when addressing children.

You is rendered in Spanish by vos, vosotros (mas.) vosotras (fem.) and also usted (Ud. or V.) for the singular or both genders, and ustedes (Uds. or VV.) for the plural.

Vos is used only in formal style, or when addressing the Deity, saints, kings, etc. Vosotros is used by orators and speakers.

Usted in the singular and Ustedes in the plural is the only form of direct address that a stranger is likely to use.

It is the universal conversational expression; as vosotros is rarely used, and tú marks a decided familiarity $(20.01 .1917,2 b)$.

Recordemos en este lugar, que estos cursos iban dirigidos probablemente en su gran mayoría a hombres de comercio norteamericanos ${ }^{28}$ y eran

27 Si bien es sabido que en el ámbito periodístico las páginas impares tienen mayor valor que las pares dentro del periódico; este desplazamiento llama la atención y nos puede servir como indicio de que el curso fue interrumpido por motivos que ignoramos. Agradecemos a Luis Bernardo Quesada Nieto este y otras valiosos comentarios e informaciones que nos ha hecho a lo largo de la elaboración de este artículo.

28 Como recalcaban en uno de los textos bilingües introductorios al curso e interesantemente solo en la parte inglesa: "Everybody is more or less informed of the enormous business development in South American trade and of the future opportunities that these countries present to those people that learn their language, their habits, their means, that become acquainted with its resources, business conditions, etc. / The better the American business people know their language, the better is the opportunity to get the benefits, thereof. / In this section of "La Prensa", the student of Spanish will find in the future details of those countries such as their produce business opportunities, description of cities, habits, of the people, the 
concebidos para el aprendizaje de un español comercial para ser empleado en Hispanoamérica y durante una época en la que el tú todavía no estaba aún tan difundido como hoy en día (cfr. Brown / Gilman 1964). No nos ha de extrañar pues que usted (como forma de respeto)/ ustedes (como forma de respeto y la única empleada en Hispanoamérica para el plural) sean las formas recomendadas. Mientras que la descripción del uso de vos evoca reminiscencias de la mismísima gramática de Bello: "pero ahora no se usa este vos sino cuando se habla a Dios o a los Santos, o en composiciones dramáticas, o en ciertas piezas oficiales donde lo pide la ley o la costumbre" (Bello 1847 [2002]: 234) ${ }^{29}$.

Por lo demás, y siempre en la línea del interés comercial, se dedican algunas lecciones al vocabulario de la correspondencia (27.01.1917, 2a-b), a las abreviaturas mercantiles más usadas $(03.02 .1917,2 \mathrm{a}-\mathrm{b})$ o a algunos sistemas de medidas (17.02.1917, 2a-b; 24.02.1917, 2a-b), a la fraseología (10.02.1917, 2a-b) o a los proverbios (24.02.1917, 2a-b). También se le dedican dos entregas a "the description of South American countries" con textos generales sobre Chile ${ }^{30}$ (03.03.1917, 2a-b; 17.03.1917, 2a-b).

Tras el curso Galeno, La Prensa publicó el "Morrell Commercial Course of Spanish" "by Henry B. Morrell of the faculty of Commercial HighSchool of Brooklyn" entre el 07 de abril de 1917 y el 18 de agosto de 1917, en 20 lecciones. Dado el éxito que supuso la publicación de este curso, el periódico lanzó una segunda edición a partir del 29.09.1917. Esta segunda edición prometía restringirse aún más a lo meramente comercial (factor que ya de por sí estaba presente en el título), esta vez como nos explica el periódico: "The new lesson will be made even more practical by the suppression of all topics that are not strictly of commercial adaptation, and every effort will be made to fill the very apparent lack of suitable introduction to the Spanish of Commerce" (p. ej., 25.08.1917, 7f-g) ${ }^{31}$.

best way to travel, the cost of these trips and in fact everything that will serve to practice language and at the same time, give a true idea of the Southern Republics" $(13.01 .1917,2 \mathrm{~b})$. Las cursivas son nuestras.

29 Lamentablemente no hemos podido consultar la Gramática de la lengua castellana de la RAE, que por esos entonces andaba entre la vigésimonovena y la trigésima edición (cfr. $<$ http://www.rae.es/la-institucion/historia/siglo-xx>). En general resulta difícil saber cuáles pudieron ser las fuentes gramaticales de este tipo de cursos.

30 Chile parece ser uno de los países con más interés económico, probablemente por la riqueza de recursos naturales, como desprendemos de los textos mismos. En la entrega del 24 de febrero de 1917 se explica además el sistema monetario chileno.

31 Por motivos de espacio prescindimos de un análisis pormenorizado de este y demás cursos; nos reservamos este ejercicio para otra publicación. 
Durante los años 1918/1919 se publica de manera más esporádica e irregular el "Intermediate Course in Commercial Spanish", que parece ser una continuación del "Morrell Commercial Course of Spanish", también concebido por el profesor Henry B. Morrell de la Commercial High School of Brooklyn. Durante estos años, el periódico se ve reducido a seis páginas hasta mayo del 1919 debido a la carestía de papel por la I Guerra Mundial, a cuyas noticias se dedicará el periódico de manera significativa al menos hasta finales del 1918.

Durante la década de los 1920, desaparecen los cursos de lengua casi por completo, si bien durante los primeros meses del año 1920 se publica aún "A Practical Course in Conversational Spanish". Nos atrevemos a conjeturar que la desaparición de los cursos de lengua durante esta década tiene que ver con el hecho de que éstos ponían demasiado énfasis en el argumento comercial, argumento que, como hemos visto, carecía de prestigio a los ojos de los hispanistas de la época. Recordemos también que el llamamiento a la campaña de prestigio por parte de Warshaw databa del año 1919 (cfr. cap. 2).

Volverán a aparecer cursos para aprender español durante la década de los 1930 y se seguirán publicando hasta mediados del siglo xx. Así se publicarán por ejemplo durante los años 1940 la "Spanish Lesson", una rúbrica más o menos fija que abarcó diferentes tipos de cursos de lengua. Suponemos que la publicación de este tipo de material, más allá del periodo del Spanish craze, siguió debiéndose a motivos económicos y por seguir los formatos y contenidos de la era Camprubí, que tan prolífica había resultado ${ }^{32}$.

\subsubsection{El Eco de las Aulas}

A raíz de una serie de reformas que el periódico comienza a hacer a partir del año 1921, aparece, sin embargo, a partir del 1 de enero de 1921 la rúbrica "El Eco de las Aulas", que según el rotativo había de dedicarse "exclusivamente a recoger las palpitaciones de la vida escolar en las cátedras de castellano" (14.12.1921, 1e) de EE.UU.

32 De hecho, el periódico continuará teniendo los mismos contenidos y rúbricas (o muy similares) también después de la muerte de Camprubí, como anunciaba en un editorial dos días tras su fallecimiento: "Pero no hemos perdido al señor Camprubí. No le veremos más, pero en todos los rincones del periódico seguirá viviendo espiritualmente; y por no poderlo olvidar, cuando nuestro ánimo flaquee, su recuerdo nos estimulará para continuar en la brega, haciendo que LA PRENSA siga siendo lo que él quería" (14.03.1942: 3a). 
Desde un comienzo los coordinadores de esta rúbrica vieron la necesidad de justificar su existencia sobre todo con respecto a revistas especializadas dedicadas a temas de didáctica:

Aunque tenemos muy en cuenta que en Norteamérica existen revistas meritísimas que dedican a las cuestiones de enseñanza una atención preferente y hasta exclusiva (como ocurre con la insuperable publicación "Hispania", órgano de la Association of Teachers of Spanish), no vacilamos en asegurar que emprendemos la creación de "El Eco de las Aulas", con el propósito de llenar un enorme vacío, ya que, cuando un organismo adquiere la vitalidad que ha adquirido el que forman los miles y miles de personas dedicadas a enseñar o a aprender el castellano, hay aspectos profesionales que, por su índole especial, tienen en una revista técnica el lugar más indicado para su desarrollo, hay otros, en cambio, que caben lo mismo en la revista técnica que en la miscelánea; y no deja de haber muchos, que, por su urgencia, por su interés momentáneo, por su extensión y por otras varias razones, sólo pueden manifestarse en una publicación diaria. Entiéndase, pues previamente, que nuestra afirmación de que pretendemos llenar un vacío no implica el menor alarde de superación ni de competencia. Queremos simplemente trabajar en un ancho campo, en el que vemos grandes extensiones baldías; queremos trabajar poniendo en la tarea todo nuestro esfuerzo y buena voluntad y viendo en todo aquel que labore a nuestro lado en tareas análogas, un compañero fraternal, cuando no un maestro $(14.12 .1920,1$ e).

No sorprende que se mencione Hispania, la revista lanzada en 1917 por la AATS, pues, Camprubí y el periódico tuvieron que estar en contacto con la asociación. De hecho, a partir del año 1924, La Prensa lanzaría en colaboración con ésta un concurso de ensayos de estudiantes de español, cuyos textos premiados se publicaron en el periódico a lo largo de los años 1924-1928 (cfr. cap. 4.2.3.). Alegando el argumento de la periodicidad y de la urgencia de informar acerca de las actividades del aula, entre otras cosas, se justificaba la aparición de esta rúbrica y se apelaba a la colaboración entre las instituciones. Además, el campo de "los miles y miles de personas dedicadas a enseñar o a aprender el castellano" era lo suficientemente "ancho" y "baldío" como para que el periódico pudiera y debiera hacer sus propias incursiones.

Durante los primeros cuatro meses, la cabecera de la sección rezó lo siguiente: "Página especialmente dedicada a los alumnos de lengua y literatura española, a cargo de Juan Cueto, de Columbia University"; sin embargo, esta inscripción desaparece a partir del28 de abril de 1921 (cfr. nota 35$)$. En un principio la rúbrica lo quiso abarcar todo: 
$\diamond$ una "Sección informativa" que informara acerca de las actividades que se dieran en "Universidades, Colegios, Escuelas y sociedades hispanistas" $(01.01 .1921,4 b)$, para las cuales se pidió desde un comienzo ayuda a "los profesores y alumnos de las clases de español" (01.01.1921, 4a). La sección prometía dedicarle, además, artículos a "personalidades, con quienes la enseñanza del castellano ha contraído una mayor deuda de gratitud”, amén de describir "las organizaciones más eficientes en el aspecto cultural (American Association of the Teachers; Instituto de las Españas; Hispanic Society, etc.)" (01.01.1921, 4c);

$\diamond \quad$ "Literatura miscelánea" en la cual se publicaran artículos literarios, "dándose preferencia a aquellas composiciones, que tengan un interés pedagógico directo y a la colaboración de escritores dedicados a la enseñanza o relacionados con ella" $(01.01 .1921,4 \mathrm{c})$;

$\diamond$ "Artículos didácticos" relacionados con aspectos concernientes al folletín (cfr. infra) y a la sección de consultas también publicados en esta página;

$\diamond \quad$ una "Sección de consultas" 33 a la que pudieran acudir los lectores, con el objetivo de "establecer una plataforma, en que puedan recibir el aire y la luz de una discusión serena las cuestiones más oscuras y más discutibles de gramática, de lexicografía -y de las demás ramas de la ciencia del lenguaje" (01.01.1921, 4c);

$\diamond$ una "Sección bibliográfica" que recogiera reseñas de libros y revistas de interés;

$\diamond \mathrm{y}$, por último, en formato de folletín ${ }^{34}$, “obras maestras de la literatura española e hispano americana, escogiéndolas entre aquellas, que sin mengua del mérito literario, ofrezcan amenidad para la generalidad de los lectores" (01.01.1921, 4d), empezando por la obra del siglo XVI "Historia del Abencerraje y de la hermosa Jarifa", seguido de "Idilios Vascos" de Pío Baroja o "Marianela" por Benito Pérez Galdós, para mencionar los tres primeros.

Como vemos y como ya hemos comentando anteriormente, se trata de una serie de contenidos y formas muy heterogéneas que bien tenían por objetivo informar acerca de las actividades, bien poder ser empleados para

33 Esta sección no llegó a establecerse nunca, probablemente por falta de consultas por parte de los lectores, como desprendemos de uno de los dos únicos artículos que se llegaron a publicar el 19.01.1921 y el 02.02.1921. En el primero, Cueto deploraba el hecho de no haber anunciado la sección con antelación.

34 Otro "moyen de marketing que surge durante el siglo xIX en la prensa francesa" (Grosse y Seibold 1994: 52). 
las aulas de español. Sin embargo, tanto quiso abarcar este cajón de sastre de aparición diaria y con tantos apartados que parecían solaparse, que la ambiciosa empresa, al cabo de cuatro meses, cuando el profesor Cueto deja su dirección ${ }^{35}$, tuvo que ser reestructurada. A partir de ahí la rúbrica que disponía en un comienzo de la superficie de toda una página (y a veces más), la 4, la que solía ser la de opinión o la de información cultural, se irá reduciendo a algunas columnas y ya no se publicará ni de manera regular ni diaria, al menos durante este año. A pesar de todos los cambios y reformas a las que se vio sometida durante su existencia, se mantuvo durante unos ocho años.

Al igual que había sucedido con los cursos de lengua, también esta rúbrica será publicitada por el diario para fines comerciales, incitando a los profesores a suscribirse a las series, vendiéndolas a 50 centavos mensuales por pago adelantado. También les ofrecían enviar el periódico "en varios ejemplares juntos" (13.01.1922, 4c). Todo ello sirviéndose de un cupón impreso en la misma página. Esto da una vez más fe del grado de comercialización que podemos hallar durante esta época preglobalizada en torno a la lengua y el aprendizaje de ésta: la enseñanza se va perfilando ya como todo un mercado y rica fuente de ingresos para el periódico.

A lo largo del año 1928, la rúbrica se acabará confundiendo con aquella que lleva por título "Notas Escolares", que existía ya desde 1925 y que pasó a dar información acerca de las "actividades de los Círculos de español, las Escuelas, «Colleges» y Universidades" $(01.01 .1925,4 \mathrm{f})$ proporcionada por los lectores, ya que "El Eco de las Aulas" había quedado reducido a proporcionar textos literarios que se pudieran emplear en clase. El componente literario, que ya existía anteriormente a la época del "Eco de las Aulas" tambiénse seguirá publicando, así p. ej., "El cuento de hoy".En efecto, parte de los contenidos ya habían estado antes de la aparición de esta rúbrica y seguirán estando ahí. Lo que se pierde de alguna manera es el factor publicitario/económico dirigido explícitamente al cuerpo de profesorado y estudiantil, que implícitamente ya había conllevado antes de la instauración de esta rúbrica ${ }^{36}$. En cuanto a la selección literaria, lo que cambiará en el "Eco de las Aulas" será según el periódico lo siguiente:

35 El periódico no da ningún tipo de explicación de por qué se termina esta colaboración, pero suponemos que se debió a la dificultad de compaginar la labor universitaria y la de coordinación de una rúbrica periodística diaria de tal envergadura.

36 Así encontramos, por ejemplo, el 17.11.1917, 7a-b este anuncio: TO THE AMERICAN STUDENT OF SPANISH / Beginning with this number we are giving selected pieces of translated literature from distinguished authors in good and correct Spanish in order that our students may practice reading good literature and those more advanced, may translate them into English. / By means of these selected articles, the students will not only practice 
Este periódico venía dedicando una página entera a la amena literatura, escogiendo los temas entre aquellos [que] tuvieran un interés directo para la colonia de habla española. En la elección del folletín, por ejemplo, venía predominando el criterio de las traducciones de libros escritos en inglés, en los que los españoles o hispanoamericanos recién llegados podían encontrar un texto vivo, que les ayudase en la tarea de penetrar en el alma del pueblo en que había venido a vivir. Aunque hay muchos puntos de vista, desde los cuales puede defenderse ese criterio, a nadie se le ocultará que con la transformación que vamos a intentar en esta hoja, al atender preferentemente los intereses de un grupo-el formado por el gigantesco cuerpo de maestros y alumnos-serviremos, mejor que antes, los intereses generales, puesto que el núcleo de españoles e hispano americanos, que viven aquí y que reciben, en cada paso que dan, una lección de americanismo, están más necesitados de textos castizos, en que se mantenga el fuego sagrado de su raza: de lecciones, que aminoren el detrimento, que siempre produce en la contextura del idioma propio el ejercicio cotidiano de un lenguaje distinto, de informaciones relativas a los libros /[4b] nuevos, a las conferencias, discursos, fiestas y reuniones, que se celebren aquí, a las que acaso pueda asistir, proporcionándose el regalo de vivir unas horas en el ambiente de su tierra. Todo esto aparte de la honda satisfacción patriótica, que debe producir en todo individuo de habla española el hecho de ver reflejados a diario, en las columnas de un periódico, el movimiento y la vida de ese organismo tan formidable que constituyen, en su conjunto, los miles y miles de personas, que se dedican a la enseñanza y al estudio del español (01.01.1921, 4a-b) ${ }^{37}$.

Como vemos, el énfasis de servir a la integración del inmigrante mediante la publicación de traducciones del inglés para familiarizarlo con la sociedad de acogida es desplazado por el valor patriótico que consiste en proporcionarle "textos castizos" para mantener "el fuego sagrado de su raza" y aminorar el detrimento que "siempre produce en la contextura del idioma propio el ejercicio cotidiano de un lenguaje distinto". Este último punto resulta ser un ideologema recurrente en la prensa (Cameron 1995: 68): nos encontramos aquí ante el usual miedo de contaminación lingüística que es tan frecuente en este tipo de contextos plurilingües y transnacionales (Joseph 1987: 30; Paffey 2012: 16). Con la nueva rúbrica se matan así varios pájaros de un tiro al "atender preferentemente los intereses" del grupo "formado por

the Spanish language, but will also enable them to gather good and valuable observations of authors of all nationalities and races.

37 Las cursivas son nuestras. 
el gigantesco cuerpo de maestros y alumnos", un público receptor muy lucrativo, lo cual se vende como un ejercicio de mejora de este servicio que además resulta ser servicio patriótico ${ }^{38}$. Obsérvese además cómo se emplea el término emblemático de raza ligado al movimiento del hispanismo (cfr. Sepúlveda Muñoz 1994: 254-276), junto con otros términos ${ }^{39}$ recurrentes como el de "colonia de habla española" o "núcleo de españoles e hispano americanos" para homogeneizar a este conglomerado ya por esos entonces bastante heterogéneo. Está operando aquí muy tempranamente el proceso semiótico de elisión (Gal / Irvine (1995: 972 y ss; del Valle 2006: 42), lo cual también puede ser visto como una estrategia para mantener el colectivo de lectores lo más amplio posible también en cuanto a la comunidad de inmigrantes.

Al igual que la práctica de emplear el periódico, era y sigue siendo también muy común la de emplear textos literarios para el aprendizaje de las lenguas. Ya que la lengua literaria suele ser considerada como la base de la variedad estándar (Crowley 2003: 84; Paffey 2012: 48). El mismísimo Menéndez Pidal recomendaba a los profesores de español estadounidenses en uno de los artículos programáticos publicados en el primer número de Hispania lo siguiente:

Por lo tanto la enseñanza de la lengua debe tender a dar un amplio conocimiento del español literario, considerado como un elevado conjunto; $y$ de un modo accesorio debe explicar las ligeras variantes que se ofrecen en el habla culta española en España y en Hispano-América, haciendo ver la unidad esencial de todas dentro del patrón literario (Menéndez Pidal 1918: 11).

Menéndez Pidal proponía así una representación del español como un conjunto altamente unificado de variedades en el que el español literario había de ejercer como norma escrita y el habla de Castilla como norma oral (del Valle 2014a: 98). Esta parece ser la pauta que sigue también el periódico, favoreciendo, todo en la línea del ilustre filólogo español, la

38 El patriotismo/nacionalismo vinculado al ejercicio de aprender otra lengua y a los intereses económicos y políticos fue otro ideologema recurrente durante esta época, así afirmaba Wilkins: "Cuando una nación tiene un comercio inmenso y relaciones estrechas con otras naciones que hablan distintos idiomas, prevalece en ella forzosamente un punto de vista nacional respecto al aprendizaje de lenguas, que puede diferir mucho del que se tiene en alguna otra nación, que en su mayor parte se baste a sí mismo económica y políticamente" (1922: 85).

39 Véase Sánchez (2016) para la evolución de este tipo de términos de autodefinición en la prensa hispanófona neoyorquina durante la primera mitad del siglo XX. 
variedad ibérica, pues como ha estudiado Amparo de Juan Bolufer, "abundan [en general, no solo en esta rúbrica] los escritores españoles del siglo XX, y firmas consagradas, pues este periódico es muy poco arriesgado en su selección" (2009: 544), lo cual era, al parecer,asimismo la práctica común en las publicaciones hispanófonas neoyorquinas de la época (2009: 545).

Podemos pues decir que a través de la selección y publicación de este tipo de textos en una rúbrica declarada abiertamente como escolar, el rotativo estaba reproduciendo y reafirmando una vez más determinados regímenes de normatividad profundamente anclados en la ideología del hispanismo estadounidense de la época (del Valle 2014a: 360).

Aunque los propios profesores de español no siempre estaban de acuerdo con el uso de literatura, sobre todo en el caso de las clases de principiantes, como advertía Lawrence A. Wilkins:

Nos parece que las diferencias que existen entre el español literario y el familiar o de todos los días, son más imponentes que las que se perciben en francés, alemán o italiano. Al lado de esta declaración hay que poner esa otra, que reza que de todos los idiomas de hoy que se enseñan en los Estados Unidos, el español posee la significación práctica más evidente. Entonces se deduce fácilmente que la lectura de trozos en alto grado literarios durante los primeros años de estudio del idioma es, si se me permite la frase, una tontería; por lo menos un tour de force absolutamente injustificado. No se adquiere el vocabulario práctico y útil que hace falta, ni se logra una estimación debida de las obras maestras de la literatura. Si fueran autores contemporáneos los que se leen, no sería tan disparatado el procedimiento como ya es de suyo, porque entonces se conocería el vocabulario literario del día de hoy [...] (Wilkins 1922: 128).

\subsection{CONCURSOS}

Otra estrategia publicitario-comercial que aplicó el rotativo durante estas décadas del Spanish craze, implicando una vez más a este lucrativo público receptor-consumidor que suponía "el gigantesco cuerpo de maestros y alumnos" (01.01.1921, 4a), entre otros, fue la de organizar certámenes de composición. Se trata de otra manera más de atraer, tratar de comprometer e involucrar a lectores potenciales - práctica que era muy popular ya desde finales del siglo XIX en el mundo periodístico (Weill 1934: 165)-, esta vez ofreciéndoles una manera más activa de implicarse, seduciéndoles además con algún tipo de recompensa. 
Fueron también múltiples los concursos que se convocaron desde las páginas de La Prensa a lo largo del periodo estudiado y estos dan una vez más fe de la estrecha colaboración con los centros e instituciones de enseñanza. Hacia finales de 1917 se organiza, por ejemplo, un "Certamen de composición en inglés en colaboración con el Departamento de Inglés para Extranjeros de la West Side Young Men's Christian Association" (17.11.1917, 7d-e); el premio era "un curso completo de gramática, composición y conversación inglesa dado por el Departamento de Inglés para Extranjeros de la West Side Y.M.C.A., 318 West 57th Street" (24.11.1917, 7d-e); el tema de la composición fue "La parte que al nuevo mundo corresponde en la guerra", con una extensión máxima de 300 palabras $(24.11 .1917,7 d-e)$. La composición ganadora fue publicada en el periódico, suponemos que durante las primeras semanas del año 1918, de las cuales lamentablemente no disponemos de ningún número. Este concurso se inscribe más bien en la línea de integración del inmigrante que el periódico, como hemos visto, también adoptó, sobre todo durante la etapa previa a la década de los 1920.

Otra serie de concursos dignos de mención fueron los organizados durante los años escolares del 1924-1928 a nivel nacional, en colaboración con la AATS en el marco de la rúbrica "El Eco de las Aulas". Se trató más concretamente de un concurso de ensayos de estudiantes de español, cuyos textos premiados se publicaron en el periódico a lo largo de estos años. Como objetivo declaraban el "dar mayor impulso e incrementar el entusiasmo por el estudio del idioma español en los Estados Unidos" (10.03.1927, 4c-e) y "estimular a los estudiantes norteamericanos en el estudio del español y con ello lograr que se interesen en la literatura y en las otras manifestaciones culturales de nuestra raza" (16.05.1928, 4g-h). De nuevo hallamos el término clave del hispanismo, raza, en función del ideologema cultural de prestigio.

"LA PRENSA distribuyó \$3.500.00 en NOVENTA PREMIOS entre los alumnos y maestros de español de los centros de enseñanza de este país" (10.03.1927, 4c-e), cifra no desdeñable para esos entonces, en lo que el rotativo llegó a denominar una "altruista causa" (16.05.1928, 4g-h).

Cinco fueron los grupos de participantes propuestos que cubrían los niveles superiores del sistema educativo estadounidense:

a) "Alumnos de las Escuelas Superiores (públicas y privadas)"

b) "Alumnos de los «Colleges»"

c) "Alumnos de los colegios y universidades, aspirantes al título de A. M. en Lenguas Romances"

d) "Aspirantes al grado Ph.D. en Lenguas Romances"

e) "Profesores de Español en las Escuelas Superiores"; 
Seis las regiones en las que celebró:

I) Estados de Maine, New Hampshire, Vermont, Massachusetts, Rhode Island, Connecticut, New York, New Jersey, Pennsilvania

II) Delaware, District of Columbia, Maryland, Virginia, West Virginia, North Carolina, South Carolina, Georgia, Florida, Alabama, Mississippi, Tennessee, Kentucky, Porto Rico

III) Ohio, Indiana, Illinois, Michigan, Wisconsin, Iowa, Minnesota, Missouri, Arkansas, Louisiana

IV) North Dakota, South Dakota, Nebraska, Kansas, Colorado, Wyoming, Montanta, Idaho, Washington

V) Arizona, Utah, Nevada, California, Oregon

VI) los Estados de Texas, New Mexico y Oklahoma.

Los ensayos se publicarían, según el rotativo, tal como los alumnos los habían presentado al concurso "sin correcciones de los errores que pudieran contener, con el objeto de que los lectores puedan darse cuenta precisa del adelanto de los estudiantes de español en las escuelas americanas" (10.03.1927, 4c-e). Los temas estaban relacionados con el ámbito cultural del mundo hispanófono.

El último ejemplo que traemos no es fruto de la colaboración con instituciones de enseñanza, pero sí tiene como objetivo promocionar el español en un marco bastante emblemático.En mayo de 1919, La Prensa organizaba por primera vez unos juegos florales en Nueva York, la celebración tuvo lugar en Carnegie Hall el 04.05.1919.

Tres fueron las categorías convocadas con sus respectivos premios ( $\mathrm{p}$. ej., 31.03.1919, 6c-e):

I. Poesía lírica: tema libre: extensión máxima 100 líneas. Premio: La Flor Natural con el privilegio de elegir la Reina de los Juegos Florales. Recompensa adicional, \$250.

II. Prosa: "Unidad espiritual y material de la América hispana y anglosajona”. ¿Por qué no se ha logrado? ¿Cómo puede obtenerse efectiva y prontamente? Extensión máxima, 3500 palabras. Premio: Un objeto de arte. Recompensa adicional, $\$ 500$.

III. Cuento en prosa: tema libre; extensión máxima, 2500 palabras. Premio: Un objeto de arte. Recompensa adicional, \$200

El jurado calificador fue integrado por Federico de Onís, José Castellot, el poeta Tomás Walsh, Oreste Ferrara y Pedro Henríquez Ureña, aunque en el 
artículo sobre la gala solo se mencionan los primeros tres $(05.05 .1919,1 \mathrm{a})$. Ganador del premio principal fue el poeta mexicano Joaquín Méndez Rivas, que al parecer ya había ganado la flor natural de otros juegos florales (los de Oaxaca y Covadonga, entre otros) (cfr. 05.05.1919, 1e), el cual "escogió como reina de la fiesta a la señorita Luz Requena Legarreta" (05.05.1919, 1a), de la cual el periódico no nos da ulterior información.

Así, un año después de la instauración y celebración en Nueva York de una fiesta tan emblemática como el Día de la Raza ${ }^{40}$ (cfr. Pike 1971: 172 y ss.; Sepúlveda Muñoz 1994: 270-276), el rotativo se embarca en otra empresa de alta carga simbólica e histórica en el mundo iberoamericano, en la que la lengua española había de fungir una vez más como ente articulador:

con el propósito de vigorizar y estrechar el afecto recíproco entre los habitantes de origen hispano y de origen anglo-sajón del continente americano, así como de contribuir a la expansión del conocimiento del idioma español en los Estados Unidos de América y a dar a esa nuestra lengua mayor lustre y belleza. $(15.01 .1919,1 \mathrm{c}-\mathrm{d})^{41}$.

\section{CONCLUSIONES}

El material analizado en este artículo demuestra cómo La Prensa no solo supo hacerse eco del auge y demanda de la enseñanza del español en EE.UU., sino que también supo cómo conectar con la red de instituciones que emergen a comienzos del siglo xx precisamente como reflejo, reacción y órganos ejecutores de este Spanish craze que se estaba viviendo. Se posicionaba así como un importante vehículo polifuncional capaz de suplir determinadas carencias causadas por el boom (p. ej., falta de textos escolares), difundir la campaña de prestigio del español y, por supuesto, también por motivos

40 Celebrada el 12 de octubre y conocida también en determinados países hispanoamericanos ya desde el siglo xix bajo nombres como el "Día de Colón” y el "Día de América", este evento conmemora el "descubrimiento" de América. En Nueva York ya se venía celebrando desde comienzos del siglo por la comunidad de inmigrantes italianos.

41 En los próximos años la fiesta va tomando otras dimensiones y el aspecto literario es relegado cada vez más a segunda plana o anulado. Así se celebra, por ejemplo, el 07.05.1927 el Baile anual de las Flores, organizado esta vez por el Galicia Sporting Club, cuyo acto principal fue la elección de la Reina de las Flores y en cuyo jurado estuvo esta vez José Camprubí $(07.05 .1927,1 \mathrm{e})$. 
lucrativos para llegar a un público anglófono más amplio, que fuera más allá del de la colonia hispanófona.

Los años analizados corresponden a los primeros diez años de la era Camprubí, durante la cual el periódico pasó por una serie de reformas, que implicaron la ampliación y profesionalización del equipo técnico y la plantilla laboral. En el marco de estas reformas se insertan asimismo las realizadas en cuanto a formatos y contenidos, que como hemos visto, parecen haberse moldeado según las demandas del mercado, creadas a su vez por acontecimientos geopolíticos y las pautas ideológicas propuestas por los principales agentes culturales. Ágil hombre de negocios, intelectual y miembro de la colonia hispana, la polifacética figura de Camprubí reunía todas las calidades para llevar a cabo la empresa de tender puentes entre ambos continentes, en un proyecto que James Fernández y Pilar Cagiao han etiquetado como "ecléctico" (2016).

El material analizado muestra claras correlaciones entre los cambios de contenidos del rotativo y factores externos que tienen que ver con el desarrollo ideológico del Spanish craze. Según nuestra lectura serían perceptibles en la transición de la década de los 1910 a la de los 1920 dos tendencias que parecen solaparse y complementarse. Por una parte, tenemos el cambio de énfasis en miras de una ampliación del público receptor, que desplaza su atención por la integración del inmigrante, proyecto que no se abandona del todo, pero que se parece subordinar a uno de mayor envergadura, el de acoplarse a las necesidades del profesorado/alumnado de ELE. Por otra parte, La Prensa parece también reaccionar a la campaña de prestigio, abandonando contenidos que recalcaban el ideologema utilitario/ económico (tales como los cursos de lengua), e implementando formatos que realzaran el cultural/prestigioso ("El Eco de las Aulas" o algunos de los concursos).

El periódico seguía con ello las ideologías recurrentes en ámbitos intelectuales y las tendencias sugeridas por la AATS en Hispania, no en vano mencionan la revista y tratan de justificar la publicación de la nueva rúbrica, "El Eco de las Aulas", con respecto a ésta en uno de los artículos programáticos. El cotejo con textos coetáneos publicados en dicha revista por importantes miembros de la asociación ha sido en ese sentido muy útil y ha servido para corroborar este solapamiento y posterior desplazamiento de ideologemas.

Hacia mediados del siglo xx (probablemente ya antes), el ideologema del prestigio cultural del español, vinculado al movimiento del hispanismo, ya está completamente consolidado en el discurso periodístico y ya no hay necesidad de mencionar el del valor comercial/utilitario (vinculado a su vez al movimiento hispanoamericanista). 
Todo esto nos permite volver a las características que comparten el ámbito de la enseñanza de lenguas y el periodístico y que con nuestro material han quedado también patentes. Con este tipo de estrategias comerciales el rotativo participaba, de alguna manera, en la legitimación de determinadas variedades por encima de otras en el mercado lingüístico, en la elaboración y difusión de un estándar y en última instancia en la construcción y reglamentación del ciudadano y de la nación-Estado. Esto resulta aún más importante en un contexto como el estudiado, que era y sigue siendo transnacional y que carecía, al menos por esa época, de instituciones que dictaran normas oficiales, como por ejemplo una academia de la lengua. Las ideologías lingüísticas vinculadas a estos procesos desempeñaron, como hemos visto, un papel fundamental. Por último, es observable cómo el español es tratado ya durante una etapa muy temprana en la que se convierte en primera segunda lengua enseñada en el sistema escolar, como un producto de mercado para un público consumidor que ya por esos entonces y, si bien bastante diferente al de hoy en día, resultase probablemente bastante lucrativo.Tendencias todas estas en torno al español en EE.UU. que siguen estando, hoy más que nunca, en el ojo del huracán.

\section{REFERENCIAS BIBLIOGRÁFICAS}

Arnoux, Elvira Narvaja DE. 2000. La Glotopolítica: transformaciones de un campo disciplinario. En Elvira Narvaja de Arnoux. Lenguajes: teorías y prácticas, pp. 95-109. Buenos Aires: Gobierno de la Ciudad de Buenos Aires, Secretaría de Educación.

2008. Los discursos sobre la nación y el lenguaje en la formación del estado (Chile, 1842-1862): estudio glotopolítico. Buenos Aires: Santiago Arcos.

Arnoux, Elvira Narvaja de y José del Valle. 2010. Las representaciones ideológicas del lenguaje. Discurso glotopolítico y panhispanismo. Spanish in Context 7.1: 1-24 [Ideologías lingüisticas y el español en contexto histórico, volumen especial editado por José del Valle y Elvira Narvaja de Arnoux].

Bello, Andrés. 1847 [2002]. Gramática de la lengua castellana destinada al uso de los americanos. Prólogo de Amado de Alonso. Alicante: Biblioteca Virtual Miguel de Cervantes. Disponible enhttp://www.cervantesvirtual.com/nd/ark:/59851/bmczk5c0 [Consulta junio 2016].

Bourdieu, PierRe. 1977. The economics of linguistic exchanges. Social Sciences Information 16.6: 645-668.

1992. Language and symbolic power. Cambridge / Maiden: Polity Press.

Brown, Roger y Albert Gilman. 1964. The Pronouns of Power and Solidarity. En Thomas A. Sebeok (ed.). Style in Language, pp. 253-276. Cambridge, Massachusetts: Massachusetts Institute of Technology.

Cameron, Deborah. 1995. Verbal Hygiene. The Politics of Language. London / New York: Routledge. 
CHTN = Carnegie Hall. Then and Now. Disponible en http://www.carnegiehall.org/ uploadedFiles/Resources_and_Components/PDF/Content/CarnegieHall_Then_and Now_2014_r0923.pdf [Consulta 24/06/2016].

Coester, Alfred. 1918. Periodicals in Spanish Available for the Classroom. Hispania 1.1: 26-30.

Cortés Ibáñez, Emilia. 2013. José Camprubí y La Prensa, pilar del Hispanismo de Nueva York. Oceánide 5: 1-13. Disponible en http://oceanide.netne.net/articulos/art5-3.php\#ref [Consulta 10/05/2016].

Crowley, Tony. 2003. Standard English and the Politics of Language. Basingstoke: Palgrave Macmillan.

De Juan Bolufer, Amparo. 2009. Recepción de la literatura española en La Prensa de Nueva York (con un apéndice sobre la visita de Blasco Ibáñez). En Javier Serrano Alonso y Amparo de Juan Bolufer (coords.). Literatura hispánica y prensa periódica (1875-1931). Actas del Congreso Internacional. Lugo 25-28 de noviembre de 2008, pp. 533-561. Santiago de Compostela: Universidade de Santiago de Compostela.

DE Onís, Federico. 1920. El español en los Estados Unidos. Hispania 3.5: 265-286.

1968. España en América. Estudios, ensayos y discursos sobre temas españoles e hispanoamericanos. Puerto Rico: Editorial Universitaria de Puerto Rico.

del Valle, José. 2006. US Latinos, la hispanofonía, and the Language Ideologies of High Modernity. En Clare Mar-Molinero y Miranda Stewart (eds.). Globalization and Language in the Spanish-Speaking World. Macro and Micro Perspectives, pp. 27-46. New York: Palgrave MacMillan.

2007. Glotopolítica, ideología y discurso: categorías para el estudio del estatus simbólico del español. En José del Valle (ed.). La lengua, ¿patria común? Ideas e idelogías del español, pp. 13-29. Madrid / Frankfurt a. M.: Iberoamericana / Vervuert.

2013. Language, politics and history: an introductory essay. En José del Valle (ed.). A Political History of Spanish: The Making of a Language, pp. 3-20. Cambrige: Cambridge University Press.

2014a. The Politics of Normativity and Globalization: Which Spanish in the Classroom? Modern Language Journal 98.1: 358-372.

2014b. Lo político del lenguaje y los límites de la política lingüística panhispánica. Boletín de Filología XLIX.2: 87-112.

del Valle, José y Vítor Meirinho-Guede. 2016. Ideologías lingüísticas. En Javier Gutiérrez Rexach (ed.). Enciclopedia de Lingüística Hispánica, pp. 622-631. New York: Routledge.

Devenish Walsh, Donald. 1967. Fifty Years of Hispania: A Chronicle. Hispania 50.4: 823-833.

FERnÁNDEZ, JAmes D. 2002. "Longfellow's Law": The Place of Latin America and Spain in U.S. Hispanism, circa 1915. En Richard. Kagan (ed.). Spain in America. The Origins of Hispanism in the United States, pp. 123-141. Illinois: University of Illinois Press.

2010. Poets, Peasants, Painters, Professors and Performers in New York. En Richard Kagan e Ignacio Suárez-Zuloaga (eds.). When Spain Fascinated America, pp. 47-59. Madrid: Fundación Zuloaga.

Fernández, James D. y Pilar Cagiao. 2016. “Campeón de los hispanos”: José Camprubí y la diáspora española en los Estados Unidos. Ponencia presentada en The Second International Congress On Historical Links between Spain and North America: Past, Present and Future, City College of New York, New York, EE.UU.

Fitz-Gerald, John. 1917. The Opportunity and the Responsibility of the Teacher of Spanish. Hispania 1.1: 11-18.

Gal, Susan y Judith T. Irvine. 1995. The Boundaries of Languages and Disciplines: How Ideologies Construct Difference. Social Research 62.4: 967-1001. 
Grosse, Ernst-Ulrich. 2001. Evolution et typologies des genres journalistiques. Essai d'une vue d'ensemble. Semen. Revue de sémio-linguistique des textes et discours 13: 1-15.

Grosse, Ernst-Ulrich y Ernst Seibold. 1994. Typologie des genres journalistiques. En Ernst-Ulrich Grosse y Ernst Seibold (ed.). Panorama de la presse parisienne: Histoire et actualité, genres et langages, pp. 32-55. Frankfurt a.M.: Peter Lang.

Habermas, Jürgen. 1974. The Public Sphere: An Encyclopedia Article. New German Critique 3: 49-55.

Haslip-Viera, Gabriel. 1996. The Evolution of the Latino Community in New York City: Early Nineteenth Century to the Present. En Gabriel Haslip-Viera y S. L. Baver (eds.). Latinos in New York. Communities in Transition, pp. 3-29. Notre Dame: University of Notre Dame Press.

Heller, Monica. 2010a. Media, the state and linguistic authority. En Sally Johnson y Tommaso M. Milani (eds.). Language Ideologies and Media Discourse: Texts, Practices, Politics, pp. 272-288. London: Continuum.

2010b. The Commodification of Language. The Annual Review of Anthropology 39: 101-114. Disponible en http://www.annualreviews.org/doi/abs/10.1146/annurev. anthro.012809.104951 [Consulta 15/05/2016].

JAKSIC, IvÁN. 2012. The Hispanic World and American Intellectual Life, 1820-1880. New York: Palgrave Macmillan.

Joseph, John EARL. 1987. Eloquence and Power. The Rise of Language Standards and Standard Languages. London: Pinter.

Kagan, Richard L. 2010. The Spanish Craze in the United States: Cultural Entitlement and the Appropriation of Spains's Cultural Patrimony ca. 1890-ca. 1930. Revista Complutense de Historia de América 36: 37-58.

Kanellos, Nicolás. 2000. A Brief History of Hispanic Periodicals in the United States. En Nicolás Kanellos y Helvetia Martell (eds.). Hispanic Periodicals in the United States. Origins to 1960. A Brief History and Comprehensive Bibliography, pp. 3-142. Houston: Arte Público Press.

Kroskrity, Paul V. 2000. Regimenting Languages. Language Ideological Perspectives. En Kroskrity, Paul V. (ed.). Regimes of language: ideologies, polities, and identities. Santa Fe, Nuevo México: School of American Research Press, 1-34.

LeavitT, S. 1967. The American Association of Teachers of Spanish and Portuguese. Hispania 50: 806-822.

LipPI-Green, Rosina. 1997. English with an Accent: Language, Ideology, and Discrimination in the United States. New York: Routledge.

MenÉndez Pidal, Ramón. 1918. La lengua española. Hispania 1.1: 1-14.

OAKLEy, EdNa. 1919. Vitalizing the Teaching of Spanish. Hispania 2.6: 291-297.

Omaggio, Alice C. 1986. Teaching Language in Context. Proficiency-Oriented Instruction. Boston: Heinle \& Heinle.

Paffey, Darren. 2012. Language Ideologies and the Globalization of 'Standard' Spanish. London: Bloomsbury.

Pennycook, Alastair. 1989. The Concept of Method, Interested Knowledge, and the Politics of Language Teaching. TESOL Quarterly 23.4: 589-618.

Pike, Fredrick P. 1971. Hispanismo, 1898-1936. Spanisch Conservatives and Liberals and their Relations with Spanish America. Notre Dame: University of Notre Dame Press.

Ruiz-Manjón, Octavio. 2012. Federico de Onís: figura clave en la historia de las relaciones culturales entre España y los Estados Unidos. Memoria y Civilización 15: 397-413.

Sánchez, Rosa. 2016. Edificando espacios comunicativo-identitarios. Términos de autodefinición en la prensa hispanófona neoyorquina durante la primera mitad del siglo 
xx. En Yvette Bürki y Henriette Partsch (eds.). Redes de comunicación: Estudios sobre la prensa en el mundo hispanohablante, pp. 249-279. Berlin: Frank \& Timme.

SCOLNIK, JuLIE. 2014. Libro de embeźar las linguas ingleśa y yudiš: La América's Guidebook to Learning English and Yiddish and Becoming an American Citizen. MEAH. Sección Hebreo 63: 1-13. Disponible en http://www.meahhebreo.com/index.php/meahhebreo/ article/view/436 [Consulta 22/05/2016].

Sepúlveda Muñoz, Isidro. 1994. Comunidad cultural e hispano-americanismo, 1885-1936. Madrid: UNED.

van DiJk, Teun. 1995. Discourse Analysis as Ideology Analysis. En Christina Schäffner y Anita L. Wenden (eds.). Language and Peace, pp. 17-33. Aldershot: Dartmouth.

Warshaw, JACOB. 1919. The Spanish Porgram. Hispania 2.5: 223-235.

Weill, Georges. 1934. Le Journal. Origines, évolution et role de la presse périodique. Paris: La Renaisance du Livre.

Wilkins, Lawrence A. 1922. La Enseñanza de Lenguas Modernas en los Estados Unidos. Conferencias dadas en el "Centro de Estudios Históricos" y en el "Ateneo", de Madrid, en el "Instituto de Idiomas" de la Universidad de Valencia y en el "Consell de Pedagogía de la Mancomunitat de Catalunya" durante el otoño de 1921. New York: Instituto de las Españas.

Yúdice, George. 2009. Culturas emergentes en el mundo hispano de Estados Unidos. Observatorio: Cultura y Comunicación, 1-75. Disponible en http://www.falternativas. org/occ-fa/documentos/culturas-emergentes-en-el-mundo-hispano-de-estados-unidos [Consulta 01/02/2015].

Páginas web consultadas:

http://centenario.eldiariony.com/cronologia/

http://www.rae.es/la-institucion/historia/siglo-xx

http://www.hispanicsociety.org/hispanic/history.htm

http://www.impremedia.com/\#intro

http://www.jae2010.csic.es/historia.php 